\title{
The Impacts of Household Financial Stress, Resilience, Social Support, and Other Adversities on the Psychological Distress of Western Sydney Parents
}

\author{
Melanie Taylor, ${ }^{1}$ Garry Stevens, ${ }^{2}$ Kingsley Agho, ${ }^{3}$ and Beverley Raphael ${ }^{4}$ \\ ${ }^{1}$ Department of Psychology, Macquarie University, Building C3A, Sydney, NSW 2109, Australia \\ ${ }^{2}$ Humanitarian and Development Research Initiative (HADRI), School of Social Science and Psychology, \\ Western Sydney University, Kingswood Campus, Building P, Locked Bag 1797, Penrith, NSW 2751, Australia \\ ${ }^{3}$ School of Science and Health, Western Sydney University, Campbelltown Campus, Building 24, Locked Bag 1797, \\ Penrith, NSW 2751, Australia \\ ${ }^{4}$ Academic Unit of Psychiatry and Addiction Medicine, Australian National University Medical School, \\ Psychological Medicine Unit, Canberra Hospital, Building 4, Yamba Drive, Garran, ACT 2606, Australia
}

Correspondence should be addressed to Melanie Taylor; mel.taylor@mq.edu.au

Received 17 January 2017; Revised 18 April 2017; Accepted 20 April 2017; Published 22 May 2017

Academic Editor: Sally Guttmacher

Copyright (C) 2017 Melanie Taylor et al. This is an open access article distributed under the Creative Commons Attribution License, which permits unrestricted use, distribution, and reproduction in any medium, provided the original work is properly cited.

\begin{abstract}
This study investigated the prevalence of psychological distress among parents in Western Sydney households and examined its relationship with household financial, family and life stressors, and potential resilience factors. As part of a longer-term study, parents from Western Sydney, New South Wales (NSW), completed computer-assisted telephone interviews (CATI) in May 2011 $(N=439)$. Respondents were primary caregivers of at least one child (aged 4-16). Responses were weighted to reflect the Western Sydney population. Multivariate analyses were conducted to examine the relationship between parent experiences of stressor and resilience factors and reported psychological distress. Overall, 10.7\% (95\% CI: 7.8, 14.5) reported experiencing high/very high levels of psychological distress. Multivariate analysis indicated that financial hardship factors formed the strongest associations with psychological distress particularly housing and job security factors and, specifically, inability to meet mortgage/rent payments $(\mathrm{OR}=5.15,95 \% \mathrm{CI}: 1.74-15.25, p=0.003)$, poor self-rated health $(\mathrm{OR}=4.48,95 \% \mathrm{CI}: 1.88-10.64, p=0.001)$, adult job loss $(\mathrm{OR}=3.77,95 \% \mathrm{CI}: 1.33-10.66, p=0.013)$, and other family/life events $(\mathrm{OR}=2.30,95 \%$ CI: $1.05-5.03, p=0.037)$. High personal resilience was common within this parent population and was a significant protective factor for high psychological distress $(\mathrm{OR}=0.14,95 \%$ CI: $0.06-0.34, p<0.001)$. The findings support the development of targeted interventions to promote parent coping strategies in the context of household financial hardship.
\end{abstract}

\section{Introduction}

The protracted economic downturns experienced in numerous countries since the Global Financial Crisis (GFC) have refocused attention on the psychological effects of financial hardship on individuals and families. Within such contexts, retrenchment or job loss, reduction of income, and associated housing stress have been linked to increased levels of distress, depression, and anxiety $[1,2]$. Even among those who are employed, the subjective experience of financial strain has been found to be a greater predictor of poor mental health than individuals' objective economic status or level of debt [1]. Australian research regarding the mental health impacts of the post-GFC period on vulnerable subpopulations has been limited. However, one longitudinal study found that anxiety and depression symptoms increased significantly among older Australians during the crisis, while depression was reported to have persisted post-GFC [3]. Parents are also a key group of interest in this context, as parental financial strain can adversely affect the functioning of households and the psychosocial development of children [4, $5]$. 
Western Sydney is often described as "middle Australia." This simple description belies the reality of a large, culturally diverse region with an estimated population of over 1.9 million people in 2011 [7] and a socioeconomic spectrum spanning affluent suburbs to pockets of significant disadvantage. Considered a potentially vulnerable region during the GFC, some analysts have argued that its aggregate effects were largely benign, with increases in unemployment being offset by government stimulus payments in 2008 and 2009 [8, 9]. Conversely, GFC related impacts may simply have exacerbated other, more pervasive factors affecting household financial security in this region. Western Sydney has a higher proportion of low income families than the rest of metropolitan Sydney [10], in part, because jobs growth has lagged population expansion. In 2006, it was estimated that there was a “jobs' shortfall" of over 180,000 positions in Western Sydney, which has continued to worsen [11]. Such factors impact housing security and associated wellbeing. Recent studies found that Western Sydney homeowners were experiencing the highest rates of "mortgage stress" in Metropolitan Sydney [12] and among the highest mortgage default rates nationally [13]. Notably, residents of suburbs reporting among the highest rates of mortgage stress (Auburn, Blacktown, and Parramatta South) also reported substantially higher rates of high or very high psychological distress, compared to residents of metropolitan Sydney (17\%-19\% and 11.8\%, resp.) [10].

There has been little research to establish the psychological effects of economic "tough times," such as the post-GFC period, on family life in Australia, particularly families with dependent children and greater exposure to economic downturns [14]. Improving our understanding of the factors that support or undermine parental coping in this context may assist the development of strategies to support households under financial strain and, importantly, mitigate adverse effects on children. As part of a wider study examining potential support interventions for families experiencing financial stress, the aim of this study was to examine the relationship between household financial strain and other life stressors on the mental health and wellbeing of parents in Western Sydney households.

\section{Methods}

2.1. Selection of Participants. The research participants were a random sample of adults (aged over 18 years) living in the western suburbs of Sydney in NSW and who live in the same household and have primary caring responsibility for at least one child aged between 4 and 16 years. The phone numbers of prospective respondents to the survey were selected via a random digit dialling process of residential numbers in the following seven area-related statistical subdivisions (SSD): Canterbury/Bankstown (0520); Fairfield-Liverpool (0525); Outer South Western Sydney (0530); Inner Western Sydney (0535); Blacktown (0553); Central Western Sydney (0540); and Outer Western Sydney (0545) (see Figure 1) [6]. The sampling framework applied was SamplePages (see http://samplepages.com.au/), and a proportional sample was drawn from the seven SSDs.
2.2. Measurements. The survey instrument was developed by the study team and incorporated a range of validated scales and items to assess parent experiences of "tough times" (i.e., financial stressors and other adverse life events) and anticipated protective factors such as perceived family and community support and personal resilience/optimism. These factors, along with other potential health and sociodemographic risk factors, constituted the independent variables of the study and were examined to determine their relationship with reported psychological distress, which was the study outcome variable. The development, deployment, and reporting of this interview-based study were completed in accordance with the Consolidated Criteria for Reporting Qualitative Studies (COREQ) guidelines [15] (see COREQ checklist, Supplementary File 1, in Supplementary Material available online at https://doi.org/10.1155/2017/6310683). The full survey protocol is presented in Supplementary File 2.

Sociodemographic information was collected which was related to the primary caregiver and their household. This included age; gender; country of birth; language usually spoken at home; highest attained education qualification; residential postcode; length of time lived in the local area; whether a single parent household; and number of children in the household under 16 years of age.

Household financial strain was examined using two items from the Household, Income and Labour Dynamics in Australia (HILDA) Survey [16] which assessed ability over the past year to pay utilities bills (gas, electricity, or telephone) or mortgage/rent payments and a further item measuring ability to pay for children's "school requirements or extras." Job loss in relation to an adult in the household in the past year was assessed as a further financial stressor due to its likely effects on household financial security and associated wellbeing.

Adverse family and life events were examined using items adapted from the Stress and Coping Inventory [17]. Respondents were asked whether they experienced the following during the previous 12 months: separation or divorce; close family member with an ongoing chronic physical health problem or disability; close family member with a mental health problem or behavioural or emotional difficulty; close family member with alcohol or drug use affecting family; persistent conflict within the family; death of a close family member; or any other experience that caused distress and worry. Parents also rated their general physical health status during the past four weeks using a validated item from the NSW Population Health Survey [18]. A large number of cross-sectional and longitudinal studies have demonstrated that self-rated heath status is a powerful predictor of future morbidity, even after controlling for a variety of health and socioeconomic factors [19]. Parent perceptions of difficulties experienced by their children were assessed using four items adapted from the Strengths and Difficulties Questionnaire (SDQ), a behavioural screening questionnaire for 4-16 year olds [20]. Perceived difficulties with each child during the past twelve months were rated on a four-point scale (none to severe). The four items reflected the factor structure of childhood difficulties as assessed by the SDQ: (1) emotional regulation, (2) concentration, (3) behaviours, and (4) peer relationships ("ability to get on with others"). 


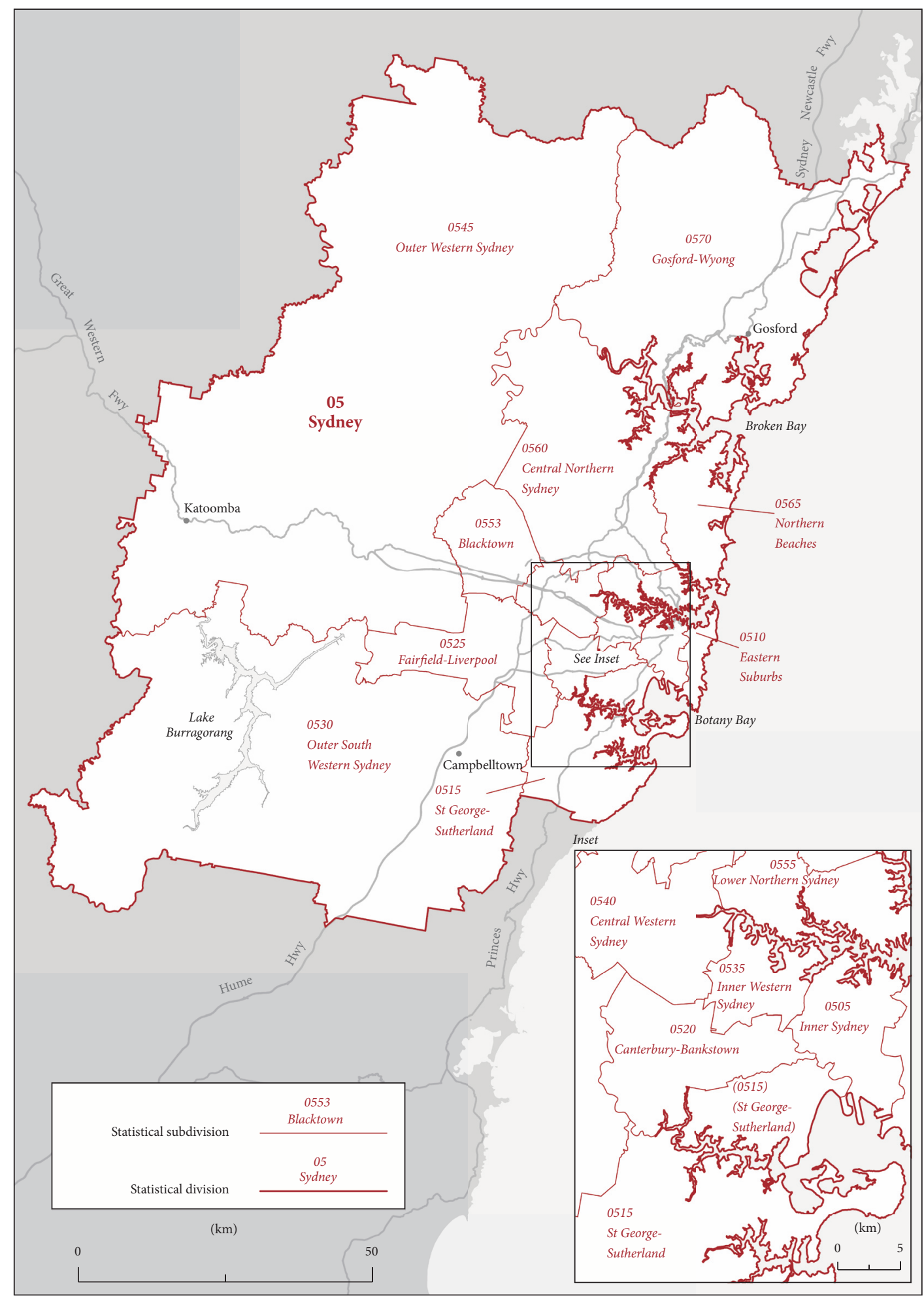

FIGURE 1: Map showing statistical subdivisions (SSD) of the Greater Western Sydney region, Australian Bureau of Statistics (2006), Australian Standard Geographical Classification (Cat number 1216.0). Canberra: Australian Bureau of Statistics [6] (permission granted for reproduction of graphic). 
Current mental health status was assessed with the Kessler 10 Measure of Psychological Distress (K10). The K10 has been used extensively in Australian population health research and provides a composite measure of nonspecific psychological distress, consisting largely of anxiety and depressive symptoms [21]. Scores on the K10 have a range of 10-50, with scores of $\geq 22$ considered to constitute "high" psychological distress. Scores in this high range have been shown to be associated with high probability of a mental disorder and have also been linked to the use of intervention strategies [22].

Personal and social support factors previously found to be associated with positive mental health status were also assessed in this study [23, 24]. Perceived social support from family and friends was assessed with two items from the Perceived Social Support Scale [25]. Social capital was measured using two items adapted from Onyx and Bullen [26], which assessed respondent trust in others and their perceived social connectedness in their neighbourhood. The short form of the Connor-Davidson Resilience Scale (CDRISC2) was used to measure current perceived personal resilience, that is, the ability to "adapt to change" and to "bounce back from illness or hardship" [24].

2.3. Data Collection. This study was approved by the University of Western Sydney Human Research Ethics Committee (Protocol number H9918). The survey was completed between 10 and 26 May 2011. The questionnaire was administered using computer-assisted telephone interviewing (CATI). Professional interviewers made up to seven calls to establish initial contact with a household and up to five further calls in order to contact the primary caregiver (hereafter "parent") of the household. The interviewers provided the respondent with the details of the project and the confidential nature of information provided prior to seeking verbal consent for participation. These methods and procedures are consistent with those used by the NSW Ministry of Health for its own data collection and used to ensure comparability of the current data with 2011 NSW population health prevalence estimates [27].

2.4. Statistical Analysis. As the respondents represented a broad cross section of the NSW adult population, the questionnaire enabled a population level examination of family experiences of tough times. The data from the survey were weighted to be representative of the Western Sydney population and to adjust for the probability of selection and differing nonresponse rates among males and females and different age groups and in a manner consistent with established NSW Health population health survey program methodology [28].

The response set for the four financial stressor questions and the nine questions regarding adverse life events were dichotomised to form the "stressor" variables of interest. "Don't know" responses were excluded from the analysis. The two personal resilience items were combined to produce a score range of $0-8$ for the CD-RISC2. Community norms for the scale indicate scores of $0-6$ and 7-8 that represent "low" and "high" self-rated personal resilience, respectively. All other individual, social support, and child difficulty variables used dichotomised ("yes"/"no") responses.

Initially, all the potential risk factors with the study outcomes in this analysis were examined with frequency tabulations and prevalence. Data analysis was performed using the "SVY" commands of Stata version 12.0 (Stata Corp, College Station, TX, USA), which allowed for adjustments for sampling weights. This was followed by univariate and multivariate analyses. Univariate analyses examined the association between the independent variables and high psychological distress.

In the multivariate model, a staged modelling technique was employed. In the first stage, all the sociodemographic and household variables were entered into the baseline multivariate model to assess their relationship with the study outcome. A stepwise backwards elimination process was conducted and variables that were significantly associated with the study outcome at 5\% significance level were retained. In the second stage, individual and community support variables were independently investigated with sociodemographic and household variables that were significantly associated with the high psychological distress. After the stepwise backwards elimination process, those with $p$ value $<0.05$ were also retained. In the third stage, financial stressor variables were independently investigated with individual and community support variables that were significantly associated with the high psychological distress. As before, those with $p$ value $<$ 0.05 were retained. A similar procedure was used in the final stage by adding adverse life event variables to individual and community support variables and financial stressor variables that were significantly associated with the study outcome. The odds ratios with 95\% Confidence Intervals were calculated in order to assess the adjusted risk of the independent variables. We also tested for, and report, any colinearity in the final model.

\section{Results}

3.1. Sample. The survey response rate was $21.6 \%$. A total of 439 parents (and therefore families/households) responded to the survey. Table 1 presents the sociodemographic characteristics of the sample. The respondents were majority female $(78.8 \%)$ with most born in Australia (66.4\%), aged between 35 and 45 years $(60.9 \%)$, and representing dualparent households (87.4\%). Having two children less than 16 years of age was the most frequently reported composition of households $(47.2 \%)$.

3.2. Psychological Distress. Figure 2 shows the prevalence estimates of reported psychological distress among Western Sydney parents compared to 2011 prevalence estimates of distress for the adult population of New South Wales in 2011. Although the respondent group was more likely to report very high levels of psychological distress and less likely to report moderate or low distress levels, none of these differences were statistically significant.

3.3. Financial Stressors and Family/Life Stressors. Respondent experiences of financial stressors and other adverse life events 


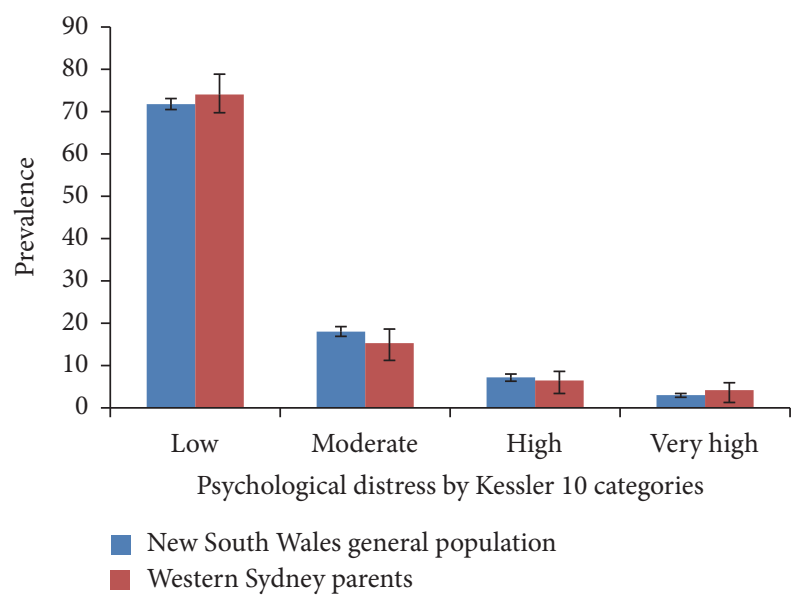

Figure 2: Past month psychological distress in Western Sydney parents and New South Wales general population.

during the previous 12 months are presented in Table 2. A total of 37 respondents (8.4\%) indicated that an adult member of the household had lost their job. Other reported financerelated stressors during this period were an inability to meet at least some scheduled payments for household utilities bills (gas, electricity, or telephone payments) (21.5\%); mortgage or rent payments $(8.6 \%)$; or school requirements or extras (16.6\%). Reported moderate or severe child difficulties and "other events" that caused distress or worry were the most commonly reported adversities of the previous year $(47.1 \%$ and $33.9 \%$, resp.), while parental divorce/separation (4.9\%) and drug/alcohol abuse that affected family functioning $(6.0 \%)$ were reported the least frequently.

3.4. Individual and Community Support Variables. As shown in Table 3, the majority of respondents reported high personal optimism (84.5\%), personal resilience $(89.9 \%)$, and interpersonal trust (64.2\%). Similarly, most reported receiving adequate social support from family $(86.2 \%)$ and friends (81.3\%). Most also reported strong connections with their community (71.1\%), although less than half (41.7\%) attended church or other formal religious services.

3.5. Univariate Analysis. The results of the univariate analysis regarding the relationship between sociodemographic/social support factors and parent psychological distress are presented in Table 4. These show that sociodemographic and household factors were not associated with the outcome variable, while positive associations were observed with several individual and community support variables. Perceived high personal resilience showed a significant inverse relationship with reported high psychological distress (odds ratio $(\mathrm{OR})=$ 0.20 , 95\% Confidence Interval (CI): 0.08-0.46, $p<0.001$ ). Reported low personal optimism was significantly associated with high psychological distress $(\mathrm{OR}=2.83,95 \% \mathrm{CI}$ : $1.26-6.35, p=0.012$ ); perceived low (inadequate) social support from family $(\mathrm{OR}=3.46,95 \%$ CI: $1.54-7.79, p=$ $0.003)$; low (inadequate) social support from friends ( $\mathrm{OR}=$ 2.43, 95\% CI: $1.10-5.37, p=0.029)$; and not having strong
TABLE 1: Sociodemographic characteristics of the sample.

\begin{tabular}{|c|c|c|}
\hline & $N=439$ & $\%$ \\
\hline \multicolumn{3}{|l|}{ Parent variables (respondent) } \\
\hline \multicolumn{3}{|l|}{ Age } \\
\hline $18-34$ yrs & 54 & 12.3 \\
\hline $35-44$ yrs & 267 & 60.9 \\
\hline $45+$ yrs & 118 & 26.8 \\
\hline \multicolumn{3}{|l|}{ Gender } \\
\hline Male & 93 & 21.2 \\
\hline Female & 346 & 78.8 \\
\hline \multicolumn{3}{|l|}{ Country of birth } \\
\hline Australia & 291 & 66.4 \\
\hline Other & 147 & 33.4 \\
\hline \multicolumn{3}{|l|}{ Highest level of education } \\
\hline$<$ Year 12 & 64 & 14.5 \\
\hline Higher school certificate & 71 & 16.1 \\
\hline TAFE certificate or diploma & 128 & 29.2 \\
\hline University/tertiary qualification & 176 & 40.1 \\
\hline \multicolumn{3}{|l|}{ Length of time lived in local area } \\
\hline$<5$ years & 73 & 16.5 \\
\hline 5 years or more & 366 & 83.5 \\
\hline \multicolumn{3}{|l|}{ Household variables } \\
\hline \multicolumn{3}{|l|}{ Household income } \\
\hline$<\$ 40,000$ & 50 & 11.3 \\
\hline$>\$ 40,000$ & 358 & 81.5 \\
\hline \multicolumn{3}{|l|}{ Single parent household } \\
\hline No & 384 & 87.4 \\
\hline Yes & 55 & 12.6 \\
\hline \multicolumn{3}{|c|}{ Number of children in household ( $\leq 16$ yrs) } \\
\hline One & 67 & 15.3 \\
\hline Two & 207 & 47.2 \\
\hline Three or more & 165 & 37.6 \\
\hline \multicolumn{3}{|c|}{ Number of children in household (4-16 yrs) } \\
\hline One & 92 & 21.0 \\
\hline Two & 225 & 51.1 \\
\hline Three or more & 122 & 27.9 \\
\hline
\end{tabular}

community connections ( $\mathrm{OR}=2.37,95 \% \mathrm{CI}: 1.18-4.78, p<$ 0.016).

Table 5 presents the results of the univariate analysis regarding the relationship between financial and life event stressors and parent psychological distress. Reported inability to meet mortgage or rent payments in the past year due to household shortage of money was significantly associated with reported high psychological distress $(\mathrm{OR}=2.83$, 95\% CI: $1.26-6.35, p=0.012$ ); inability to meet school requirements or extras $(\mathrm{OR}=3.46,95 \%$ CI: 1.54-7.79, $p=0.003)$; and an adult in the household losing their job $(\mathrm{OR}=2.43,95 \%$ CI: $1.10-5.37, p=0.029)$. Several reported adverse life events in the past year were significantly associated with current high psychological distress: having poor self-rated health $(\mathrm{OR}=6.25,95 \%$ CI: 2.92-13.38, $p<$ 0.001); child difficulties $(\mathrm{OR}=2.05,95 \% \mathrm{CI}: 1.00-4.21$, 
TABLE 2: Prevalence estimates of financial stressor and adverse family and life event variables.

\begin{tabular}{|c|c|c|}
\hline & $N$ & $\%$ \\
\hline \multicolumn{3}{|c|}{ Financial stressors } \\
\hline \multicolumn{3}{|c|}{$\begin{array}{l}\text { Could not pay gas, electricity, or telephone } \\
\text { bills }\end{array}$} \\
\hline Yes & 94 & 21.5 \\
\hline No & 343 & 78.1 \\
\hline \multicolumn{3}{|c|}{$\begin{array}{l}\text { Could not pay the mortgage or rent } \\
\text { payments }\end{array}$} \\
\hline Yes & 38 & 8.6 \\
\hline No & 399 & 90.9 \\
\hline \multicolumn{3}{|c|}{$\begin{array}{l}\text { Could not pay for school requirements or } \\
\text { extras }\end{array}$} \\
\hline Yes & 73 & 16.6 \\
\hline No & 364 & 82.8 \\
\hline \multicolumn{3}{|c|}{ Adult in the household lost job } \\
\hline Yes & 37 & 8.4 \\
\hline No & 402 & 91.5 \\
\hline \multicolumn{3}{|c|}{ Adverse family \& life events } \\
\hline \multicolumn{3}{|c|}{ Self-rated health good } \\
\hline Yes & 303 & 69.0 \\
\hline No & 135 & 30.8 \\
\hline \multicolumn{3}{|c|}{ Child difficulties } \\
\hline No & 232 & 52.9 \\
\hline Yes & 207 & 47.1 \\
\hline \multicolumn{3}{|c|}{ Persistent conflict within family } \\
\hline Yes & 67 & 15.4 \\
\hline No & 372 & 84.6 \\
\hline \multicolumn{3}{|c|}{ Parents separated or divorced } \\
\hline Yes & 21 & 4.9 \\
\hline No & 417 & 94.9 \\
\hline \multicolumn{3}{|c|}{$\begin{array}{l}\text { Chronic physical health problem or } \\
\text { disability, family member(s) }\end{array}$} \\
\hline Yes & 145 & 33.0 \\
\hline No & 293 & 66.7 \\
\hline \multicolumn{3}{|c|}{$\begin{array}{l}\text { Mental health problem, behavioural or } \\
\text { emotional difficulties, family member(s) }\end{array}$} \\
\hline Yes & 142 & 32.4 \\
\hline No & 295 & 67.2 \\
\hline \multicolumn{3}{|c|}{$\begin{array}{l}\text { Alcohol/drug use caused problems in } \\
\text { family }\end{array}$} \\
\hline Yes & 26 & 6.0 \\
\hline No & 411 & 93.7 \\
\hline \multicolumn{3}{|c|}{ Close family member died } \\
\hline Yes & 95 & 21.6 \\
\hline No & 344 & 78.4 \\
\hline \multicolumn{3}{|c|}{ Other event(s) caused distress/worry } \\
\hline Yes & 149 & 33.9 \\
\hline No & 288 & 65.7 \\
\hline
\end{tabular}

TABLE 3: Prevalence estimates of individual and community protective factors.

\begin{tabular}{lcc}
\hline Individual \& community supports & $N$ & $\%$ \\
\hline Optimistic person & 371 & \\
Yes & 68 & 15.5 \\
No & & \\
High interpersonal trust & 282 & 64.2 \\
Yes & 157 & 35.8 \\
No & & \\
Individual resilience (CD-RISC2) & 44 & 10.1 \\
Low & 395 & 89.9 \\
High & & \\
Receives adequate social support from & & \\
family & 378 & 86.2 \\
Yes & 61 & 13.8 \\
No & & \\
Receives adequate social support from & & \\
friends & 357 & 81.3 \\
Yes & 82 & 18.7 \\
No & & \\
Attend church/religious services regularly & 183 & 41.7 \\
Yes & 256 & 58.3 \\
No & & \\
Strong connections with community & 312 & 71.1 \\
Yes & 127 & 28.9 \\
No & & \\
\hline
\end{tabular}

$p=0.050)$; persistent conflict in the family ( $\mathrm{OR}=3.81$, 95\% CI: $1.76-8.25, p=0.001$ ); a family member with a chronic physical health problem/disability $(\mathrm{OR}=2.16,95 \%$ CI: $1.08-4.35, p=0.031)$; a family member with a mental health or emotional difficulty $(\mathrm{OR}=3.12,95 \% \mathrm{CI}$ : $1.56-6.27$, $p=0.001)$; or other event(s) that caused distress and worry $(\mathrm{OR}=3.65,95 \% \mathrm{CI}: 1.78-7.50, p<0.001)$.

3.6. Multivariate Analysis. The results of the multivariate analysis are presented in Table 6 and show that high current psychological distress among parents was associated with, in descending order of Adjusted odds ratio (AOR) magnitude, reported inability to meet mortgage or rent payments in the past year due to household money shortages $(\mathrm{AOR}=5.15$, 95\% CI: $1.74-15.25, p=0.003$ ); poor self-rated physical health $(\mathrm{AOR}=4.48,95 \% \mathrm{CI}: 1.88-10.64, p=0.001)$; an adult in the household losing their job $(\mathrm{AOR}=3.77,95 \% \mathrm{CI}: 1.33-10.66$, $p=0.013)$; and other adverse event(s) that caused distress and worry $(\mathrm{AOR}=2.30,95 \% \mathrm{CI}: 1.05-5.03, p=0.037)$. Reported high personal resilience had a significant inverse relationship with high psychological distress $(\mathrm{AOR}=0.14$, 95\% CI: $0.06-0.34, p<0.001)$.

\section{Discussion}

While aggregate economic impacts of the post-GFC period on "mortgage belt" Australians may have been limited, it has 
TABLE 4: Prevalence estimates and odds ratios (OR) of parent psychological distress by sociodemographic and individual/community variables.

\begin{tabular}{|c|c|c|c|c|c|}
\hline \multirow{2}{*}{$\begin{array}{l}\text { Variables } \\
\text { Sociodemographic \& household variables }\end{array}$} & \multirow[t]{2}{*}{ Prevalence } & \multirow[t]{2}{*}{ OR } & \multicolumn{2}{|c|}{$[95 \% \mathrm{CI}]$} & \multirow[t]{2}{*}{$p$} \\
\hline & & & & & \\
\hline \multicolumn{6}{|c|}{ Gender } \\
\hline Male & 11.3 & 1.00 & & & \\
\hline Female & 10.5 & 0.92 & 0.37 & 2.25 & 0.852 \\
\hline \multicolumn{6}{|l|}{ Age } \\
\hline $18-34$ yrs & 6.4 & 1.00 & & & \\
\hline $35-44$ yrs & 10.5 & 1.73 & 0.54 & 5.59 & 0.358 \\
\hline $45+$ yrs & 13.0 & 2.20 & 0.63 & 7.61 & 0.214 \\
\hline \multicolumn{6}{|l|}{ Country of birth } \\
\hline Australia & 10.3 & 1.00 & & & \\
\hline Other & 14.7 & 1.83 & 0.92 & 3.68 & 0.087 \\
\hline \multicolumn{6}{|l|}{ Highest level of education } \\
\hline$<$ year 12 & 7.0 & 1.00 & & & \\
\hline Higher school certificate & 15.4 & 2.42 & 0.76 & 7.69 & 0.135 \\
\hline TAFE certificate or diploma & 11.0 & 1.64 & 0.56 & 4.78 & 0.368 \\
\hline University/tertiary & 9.6 & 1.40 & 0.47 & 4.17 & 0.544 \\
\hline \multicolumn{6}{|l|}{ Household income } \\
\hline$<\$ 40,000$ & 14.7 & 1.00 & & & \\
\hline$>\$ 40,000$ & 10.4 & 0.67 & 0.28 & 1.61 & 0.369 \\
\hline \multicolumn{6}{|l|}{ Time living in local area } \\
\hline$<5$ years & 10.4 & 1.00 & & & \\
\hline 5 years or more & 10.7 & 1.03 & 0.40 & 2.64 & 0.951 \\
\hline \multicolumn{6}{|l|}{ Single parent household } \\
\hline No & 10.5 & 1.00 & & & \\
\hline Yes & 12.1 & 1.18 & 0.50 & 2.79 & 0.707 \\
\hline \multicolumn{6}{|l|}{ Number of children $\leq 16$ yrs } \\
\hline One & 11.6 & 1.00 & & & \\
\hline Two & 7.4 & 0.60 & 0.28 & 1.30 & 0.196 \\
\hline Three or more & 14.4 & 1.28 & 0.57 & 2.86 & 0.544 \\
\hline \multicolumn{6}{|c|}{ Number of children in household (4-16 yrs) } \\
\hline One & 10.4 & 1.00 & & & \\
\hline Two & 7.7 & 0.72 & 0.35 & 1.46 & 0.360 \\
\hline Three or more & 16.4 & 1.70 & 0.74 & 3.90 & 0.212 \\
\hline \multicolumn{6}{|c|}{ Individual \& community support variables } \\
\hline \multicolumn{6}{|l|}{ Optimistic person } \\
\hline Yes & 8.7 & 1.00 & & & \\
\hline No & 21.3 & 2.83 & 1.26 & 6.35 & 0.012 \\
\hline \multicolumn{6}{|l|}{ High interpersonal trust } \\
\hline Yes & 8.8 & 1.00 & & & \\
\hline No & 14.0 & 1.67 & 0.84 & 3.34 & 0.146 \\
\hline \multicolumn{6}{|c|}{ Individual resilience (CD-RISC2) } \\
\hline Low & 31.5 & 1.00 & & & \\
\hline High & 8.3 & 0.20 & 0.08 & 0.46 & 0.001 \\
\hline \multicolumn{6}{|c|}{ Receives adequate social support from family } \\
\hline Yes & 8.5 & 1.00 & & & \\
\hline No & 24.3 & 3.46 & 1.54 & 7.79 & 0.003 \\
\hline \multicolumn{6}{|c|}{ Receives adequate social support from friends } \\
\hline Yes & 8.8 & 1.00 & & & \\
\hline No & 18.9 & 2.43 & 1.10 & 5.37 & 0.029 \\
\hline
\end{tabular}


TABle 4: Continued.

\begin{tabular}{|c|c|c|c|c|c|}
\hline Variables & Prevalence & OR & \multicolumn{2}{|c|}{$[95 \% \mathrm{CI}]$} & $p$ \\
\hline \multicolumn{6}{|c|}{ Attend church/religious services regularly } \\
\hline Yes & 12.3 & 1.00 & & & \\
\hline No & 9.5 & 0.75 & 0.37 & 1.50 & 0.412 \\
\hline \multicolumn{6}{|c|}{ Connected with local neighbourhood } \\
\hline Yes & 8.0 & 1.00 & & & \\
\hline No & 17.2 & 2.37 & 1.18 & 4.78 & 0.016 \\
\hline
\end{tabular}

TABLE 5: Prevalence estimates and odds ratios (OR) of parent psychological distress by financial and family/life event variables.

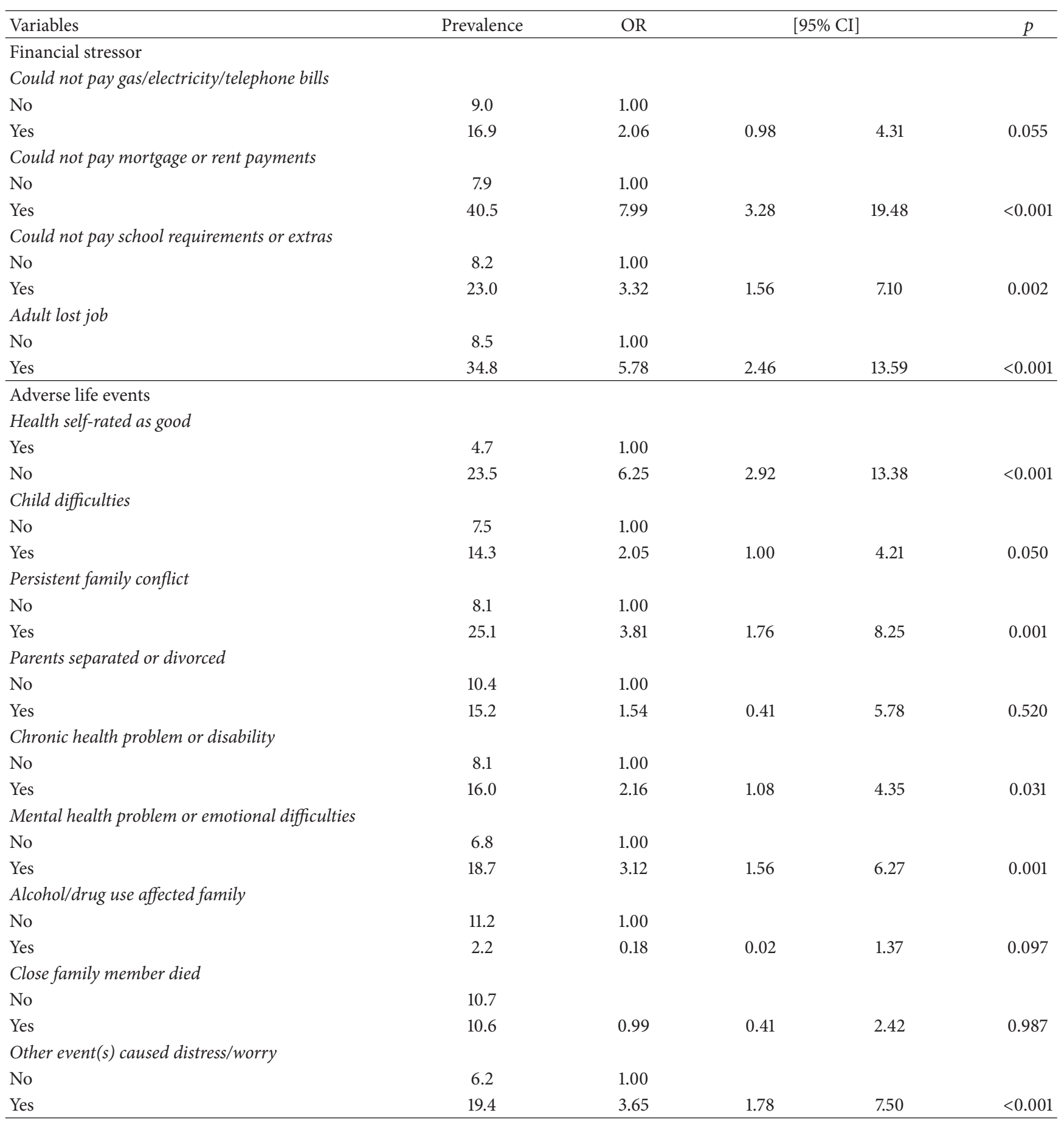


TABLE 6: Factors associated with parent high psychological distress, adjusted odds ratio (AOR).

\begin{tabular}{lcccc}
\hline Variables & \multicolumn{5}{c}{$\begin{array}{c}\text { Adjusted } \\
{[95 \% \mathrm{CI}]}\end{array}$} & $p$ \\
\hline $\begin{array}{l}\text { Could not pay mortgage or rent } \\
\text { payments }\end{array}$ & & & & \\
No & 1.00 & & & \\
Yes & 5.15 & 1.74 & 15.25 & 0.003 \\
Health self-rated as good & & & & \\
Yes & 1.00 & & & \\
No & 4.48 & 1.88 & 10.64 & 0.001 \\
Adult lost job & & & & \\
No & 1.00 & & & \\
Yes & 3.77 & 1.33 & 10.66 & 0.013 \\
Other event(s) caused & & & & \\
distress/worry & & & & \\
No & 1.00 & & & \\
Yes & 2.30 & 1.05 & 5.03 & 0.037 \\
Individual resilience & & & & \\
Low & 1.00 & & & \\
High & 0.14 & 0.06 & 0.34 & $<0.001$ \\
\hline
\end{tabular}

been argued that the "fear factor" associated with this crisis undermined consumer confidence and household financial security for an extended period [8]. Possibly more important to the economic security of Western Sydney households, however, are longer-term structural factors affecting the region; jobs "shortfalls," transport inequities, lower average incomes (affecting financial accumulation), and associated mortgage/housing "distress." Although household financial strain can adversely affect the psychosocial development of children $[4,5]$, less is known about the relative effects of such hardship on parental mental health, particularly populations that may have greater exposure to economic downturns and threats to employment [14, 29]. Overall, our findings show that when controlling for other potential confounders, financial stressors showed the strongest relationship with high parental psychological distress. Importantly, personal resilience factors were associated with lower reported distress and may represent an important protective factor for this population.

The finding that reported inability to meet mortgage/rent payments was the greatest single factor associated with reported distress which suggests that housing security constitutes one of the most critical concerns for parents in this region. Arguably, mortgage and rent repayments may be the least "discretionary" financial commitment among those assessed, particularly for families with dependent children. As such, threats to this financial capacity are likely to constitute a significant stressor for affected parents. Recent findings from the United States have shown that altered capacity to service mortgages among older adults is associated with significant elevations in the incidence of mental health problems and particularly depression [30]. The current finding, and notably its magnitude against a range of other psychosocial risk factors, highlights that parents may be a particularly vulnerable population regarding housing security during economic downturn and may warrant specific policy consideration from both economic and public health perspectives [31].

Numerous studies have shown an association between unemployment and poor mental health status [32], although few have specifically focused on the problems faced by unemployed parents and their health outcomes [29]. Notably, parent job loss and inability to meet mortgage payments were not found to be cooccurring events within the current analysis, suggesting that their relationship with high respondent distress represents distinct phenomena. While the relationship between unemployment and poor mental health is well established, debate continues regarding the most important mediators of this relationship. The "latent deprivation model" [33] posits that employment supports five key functions that underpin positive mental health (social contact, time structure, collective purpose, status, and activity), with unemployment being incompatible with these functions. Evidence in support of a more recent "incongruence model" of employment-related health [29] suggests that poor mental health is the result of dissonance that individuals experience when there is a lack of congruence between their level of employment commitment and their current employment situation. This may be an important mediating factor in the current finding for parental job loss, with the felt need to provide for family financial/material needs being dissonant with current employment status.

Specific adverse life events were associated with reported high psychological distress in the univariate analysis. These events are typically related to ongoing family-related issues such as child difficulties, family conflict, and chronic physical and mental health related problems. In contrast, more discrete stressors such as the death of a close family member and parental divorce were not associated with high psychological distress. This is consistent with findings related to the mental health effects of cumulative stress, particularly the stress diathesis model, which posits that individuals with a greater genetic or psychological vulnerability to stress may experience poorer coping in such contexts and greater risk of adverse physical and mental health outcomes [34, 35]. While specific types of adversities were not significant in the multivariate analysis, the open item regarding "other" adverse events was positively associated with parental distress and indicated that diverse and possibly cumulative stressors (e.g., caregiver issues, job insecurity, and partner relationship issues) were adversely affecting parental mental health and wellbeing.

While perceived lack of social support from family and perceived lack of social support from friends were both associated with high psychological distress, neither was found to have a significant association in the multivariate analysis. This is notable in that previous research has found a relationship between the perceived absence of social support and mental health problems among both married couples and parents, particularly in the context of financial stress [36, 37]. Similarly, "befriending" intervention programs among 
groups such as single mothers have been found to increase perceived social support and reduce identified mental health problems such as depression [38]. However, the current finding is consistent with a recent meditational analysis examining Australian parents. Crosier et al. [39] found that perceived social support did not moderate the effects of financial hardship on the mental health status of single or partnered mothers, suggesting that high perceived support may not have a substantial protective or "buffering" effect for some parent groups in these circumstances.

In contrast to some of the findings regarding social support factors, individual dispositional factors were found to have protective relationship with parental mental health. Personal optimism and resilience were both significant univariate findings. Notably, however, personal resilience also emerged as a significant finding in the multivariate analysis. Moreover, the effect size for its relationship with reported distress $(\mathrm{AOR}=0.14)$ was of a similar magnitude to reported inability to meet mortgage commitments, highlighting the importance of personal resilience as a factor protective of parental mental health. While there is evidence that dispositional optimism (i.e., stable, future-focused positive expectancy) is also associated with positive mental health status [40], the stronger finding for resilience likely reflects respondent perceptions of greater personal agency and stress coping ability, with these significantly associated with lower mental health impacts. Other studies have shown that measures of self-rated resilience reliably discriminate between general population samples and individuals experiencing clinical anxiety disorders, conditions known to be associated with stress-related reductions in coping [33]. It is important to note that approximately $10 \%$ of the parent respondent group reported low personal resilience, which the current findings indicate, conveys a higher risk of mental health difficulties. Further research could examine whether specific social or psychoeducational interventions could enhance resilience and reduce mental health sequelae among parents at higher risk of these outcomes.

The current study has important strengths and some potential limitations. The cross-sectional nature of the data limits conclusions about the direction of the observed relationships. The sample of parents that participated in the research had a greater than expected proportion of individuals with tertiary qualifications (39\%), albeit the observed rate is only marginally higher than rates recently reported for this region (31\%) [41]. Notwithstanding these limitations, the methodology of this study is well established and enabled a population level examination of family-based experiences of economic hardship, relative to a range of other common adversities and potential protective factors for psychological health.

In terms of the implications for policy, the study findings point to a range of potential avenues for national and local action. As financial factors have been found to be most strongly associated with psychological distress in this study, policy that can support household financial stability and functioning should be an important component of any policy-driven improvements for parental mental health. For example, policies that compel utility companies to offer flexible payment options to families experiencing interruptions to income or other family "crises" affecting finances could offer considerable support to vulnerable families. While some financial institutions currently offer mortgage "holidays" that allow for brief interruptions in payments and "crisis payments" in selected situations, greater policy intervention may be indicated. This is highlighted in the 2017 Reserve Bank of Australia Financial Stability Review, which reported that one-third of Australian mortgagees held savings equivalent to less than one month's repayments, providing little "buffer" against a significant financial loss or interruption [42].

Since 2011, Australia has had a National Financial Literacy strategy, led by the Australian Securities and Investments Commission (ASIC) to promote a coordinated approach to improving the financial wellbeing of Australians [43]. The availability of free independent online guidance and tools on personal finances and money management through initiatives, such as ASIC's MoneySmart, can assist in supporting population financial literacy, with the advantage of being widely accessible and available 24/7. However, there is still a place for local smaller-scale, more engaging, initiatives supported at a local government level. Opportunities to attend short face-to-face workshops, such as "You're the Boss," a financial literacy program offered by The Salvation Army [44], or access to a limited number of free financial counselling sessions, could be used to assist families with financial planning.

Beyond financial literacy, other interventions that can directly support parental coping could be considered. At a national level, groups that offer information and support online are available, for example, the Trauma and Grief Network (TGN) [45]. The TGN includes resources to support parental wellbeing and support children through times of financial hardship. At a local level, options could include opportunities to attend counselling, support groups, or dropin groups, and resources that promote free/cheap local activities for families could be used to assist.

As our study has focused on the family unit and the dynamics of parental psychological distress and child difficulties, another avenue for support should be provided for children, driven by policy directed towards the education sector or supported via local community sporting-, youth activity-, or faith-based groups. Programs to enhance resilience, social and emotional learning, peer-support, and mindfulness can be considered. Several such resources are now offered in Australia via government-funded initiatives, such as Kids Matter [46].

Any approach to improving parental psychological distress in Western Sydney (or elsewhere) is, and probably should be, multifaceted. Providing policy to support financial stability and strategies to embed financial literacy and having national resources and local initiatives to assist parents and children in managing change and dealing with stress are all likely to contribute to a more resilient and healthier society.

\section{Conclusion}

Among a range of common stressors, financial hardship factors formed the strongest associations with reported 
psychological distress among Western Sydney parents, particularly those factors related to mortgage/housing and employment security. However, reported high personal resilience was also common among parents' group and appears to represent a substantial protective factor against stress-related impacts on mental health and wellbeing. The current findings highlight the potential value of targeted interventions to support parent coping strategies in the context of identified household economic stressors.

\section{Conflicts of Interest}

The authors declare that there are no conflicts of interest regarding the publication of this paper.

\section{Acknowledgments}

The authors would like to thank Phil Hughes and staff at ORC International, who assisted with question development and conducted the data collection, and the Western Sydney families who took part in this research. This study was funded by the Health Administration Corporation on behalf of the New South Wales Ministry of Health, Grant no. H09/3740022.

\section{References}

[1] E. Turunen and H. Hiilamo, "Health effects of indebtedness: a systematic review," BMC Public Health, vol. 14, no. 1, article 489, 2014.

[2] E. Selenko and B. Batinic, "Beyond debt. A moderator analysis of the relationship between perceived financial strain and mental health," Social Science and Medicine, vol. 73, no. 12, pp. 1725-1732, 2011.

[3] K. Sargent-Cox, P. Butterworth, and K. J. Anstey, "The global financial crisis and psychological health in a sample of Australian older adults: A Longitudinal Study," Social Science and Medicine, vol. 73, no. 7, pp. 1105-1112, 2011.

[4] M. A. Barnett, "Economic disadvantage in complex family systems: Expansion of family stress models," Clinical Child and Family Psychology Review, vol. 11, no. 3, pp. 145-161, 2008.

[5] T. Raviv and M. E. Wadsworth, "The efficacy of a pilot prevention program for children and caregivers coping with economic strain," Cognitive Therapy and Research, vol. 34, no. 3, pp. 216-228, 2010.

[6] Australian Bureau of Statistics, Australian Standard Geographical Classification (Cat no.: 1216.0), Australian Bureau of Statistics, Canberra, Australia, 2006.

[7] Australian Bureau of Statistics, "Census of Population and Housing," (cat. no. 2911.0.55.002), 2011, http://profile.id.com.au/ wsroc/population?WebID $=200$.

[8] J. Norrie, “The Conversation. Income up, life satisfaction levels unchanged during GFC," July 2012, http://theconversation.com/ income-up-life-satisfaction-levels-unchanged-during-gfc-8149.

[9] Melbourne Institute of Applied Economic and Social Research and University of Melbourne, "The Household, Income and Labour Dynamics in Australia (HILDA) Survey 2012," http:// www.melbourneinstitute.com/downloads/hilda/Annual_Report/areport2012.pdf.

[10] Wentwest Medical Local Western Sydney Western, "Sydney Population Health and Workforce Needs Assessment
Summary," September 2010, https://www.wentwest.com.au/imaages/docs/WSPopulationHealthNeedsandWorkforceAssessmetSummary.pdf.

[11] NSW Department of Planning and Infrastructure, "Draft Metropolitan Strategy for Sydney to 2031," March 2013, http://strategies.planning.nsw.gov.au/Portals/0/Documents/MetroCommunityGuide.pdf.

[12] Australians for Affordable Housing, "Housing costs through the roof: australia's housing stress," Australians for Affordable Housing, Modelling commissioned from the National Centre for Social and Economic Modelling (NATSEM), Melbourne, Australia, 2011.

[13] University of Western Sydney and Urban Research Centre, "The Experience of Mortgage Distress in Western Sydney," University of Western Sydney, 2010.

[14] M. Taylor, M. Barr, G. Stevens et al., "Psychosocial stress and strategies for managing adversity: measuring population resilience in New South Wales, Australia," Population Health Metrics, vol. 8, article 28, 2010.

[15] A. Tong, P. Sainsbury, and J. Craig, "Consolidated criteria for reporting qualitative research (COREQ): a 32-item checklist for interviews and focus groups," International Journal for Quality in Health Care, vol. 19, no. 6, pp. 349-357, 2007.

[16] M. Wooden, S. Freidin, and N. Watson, "The Household, Income and Labour Dynamics in Australia (HILDA) Survey: Wave 1," The Australian Economic Review, vol. 35, no. 3, pp. 339348, 2002.

[17] R. H. Rahe, T. L. Veach, R. L. Tolles, and K. Murakami, "The stress and coping inventory: an educational and research instrument," Stress Medicine, vol. 16, no. 4, pp. 199-208, 2000.

[18] Centre for Epidemiology and Research, 2011 Report on adult health from the New South Wales Population Health Survey, NSW Department of Health, Sydney, New South Wales, Australia, 2012.

[19] E. McFadden, R. Luben, S. Bingham, N. Wareham, A.-L. Kinmonth, and K.-T. Khaw, "Social inequalities in self-rated health by age: cross-sectional study of 22457 middle-aged men and women," BMC Public Health, vol. 8, article 230, 2008.

[20] R. Goodman, "Psychometric properties of the strengths and difficulties questionnaire," Journal of the American Academy of Child and Adolescent Psychiatry, vol. 40, pp. 1337-1345, 2001.

[21] R. Kessler and D. Mroczek, Final Version: Non-specific Psychological Distress Scale, memo dated 10/3/94, Survey Research Center of the Institute for Social Research. University of Michigan, Ann Arbort (MI), Michigan, 1994.

[22] T. Slade, R. Grove, and P. Burgess, "Kessler Psychological Distress Scale: Normative data from the 2007 Australian National Survey of Mental Health and Wellbeing," Australian and New Zealand Journal of Psychiatry, vol. 45, no. 4, pp. 308-316, 2011.

[23] I. Kawachi and L. F. Berkman, "Social ties and mental health," Journal of Urban Health, vol. 78, no. 3, pp. 458-467, 2001.

[24] S. Vaishnavi, K. Connor, and J. R. T. Davidson, "An abbreviated version of the Connor-Davidson Resilience Scale (CD-RISC), the CD-RISC2: psychometric properties and applications in psychopharmacological trials," Psychiatry Research, vol. 152, no. 2-3, pp. 293-297, 2007.

[25] M. E. Procidano and K. Heller, "Measures of perceived social support from friends and from family: three validation studies," American Journal of Community Psychology, vol. 11, no. 1, pp. 124, 1983. 
[26] J. Onyx and P. Bullen, "Measuring social capital in five communities," The Journal of Applied Behavioral Science, vol. 36, pp. 23-42, 2000.

[27] M. Barr, D. Baker, M. Gorringe, and L. Fritsche, "NSW population health survey: description of methods," 2008 http:// www.health.nsw.gov.au/resources/publichealth/surveys/health _survey_method.asp.

[28] D. Steel, Population Health Survey: Review of Weighting Procedures, Centre for Epidemiology and Research, New South Wales Ministry of Health, Sydney, New South Wales, Australia, 2008.

[29] K. I. Paul and K. Moser, "Incongruence as an explanation for the negative mental health effects of unemployment: metaanalytic evidence," Journal of Occupational and Organizational Psychology, vol. 79, no. 4, pp. 595-621, 2006.

[30] D. E. Alley, J. Lloyd, J. A. Pagán, C. E. Pollack, M. Shardell, and C. Cannuscio, "Mortgage delinquency and changes in access to health resources and depressive symptoms in a nationally representative cohort of Americans older than 50 years," American Journal of Public Health, vol. 101, no. 12, pp. 2293-2298, 2011.

[31] P. Butterworth, S. C. Olesen, and L. S. Leach, "The role of hardship in the association between socio-economic position and depression," Australian and New Zealand Journal of Psychiatry, vol. 46, no. 4, pp. 364-373, 2012.

[32] F. M. McKee-Ryan, Z. Song, C. R. Wanberg, and A. J. Kinicki, "Psychological and physical well-being during unemployment: a meta-analytic study," Journal of Applied Psychology, vol. 90, no. 1, pp. 53-76, 2005.

[33] M. Jahoda, "Work, employment, and unemployment: values, theories, and approaches in social research," American Psychologist, vol. 36, no. 2, pp. 184-191, 1981.

[34] S. M. Monroe and A. D. Simons, "Diathesis-stress theories in the context of life stress research: implications for the depressive disorders," Psychological Bulletin, vol. 110, no. 3, pp. 406-425, 1991.

[35] R. E. Igram and D. D. Luxton, Development of Psychopathology: A Vulnerability-Stress Perspective, Sage, Thousand Oaks, Calif, USA, 2005, Vulnerability-stress models.

[36] CT. Whelan, "The role of social support in mediating the psychological consequences of economic stress," Sociology of Health \& Illness, vol. 15, pp. 86-101, 1993.

[37] R. Reading and S. Reynolds, "Debt, social disadvantage and maternal depression," Social Science and Medicine, vol. 53, no. 4, pp. 441-453, 2001.

[38] T. Harris, G. W. Brown, and R. Robinson, "Befriending as an intervention for chronic depression among women in an inner city. I: Randomised controlled trial," British Journal of Psychiatry, vol. 174, pp. 219-224, 1999.

[39] T. Crosier, P. Butterworth, and B. Rodgers, "Mental health problems among single and partnered mothers," Social Psychiatry and Psychiatric Epidemiology, vol. 42, no. 1, pp. 6-13, 2007.

[40] M. F. Scheier and C. S. Carver, "Effects of optimism on psychological and physical well-being: theoretical overview and empirical update," Cognitive Therapy and Research, vol. 16, no. 2, pp. 201-228, 1992.

[41] Parramatta City Council, "Summary statistics: greater western Sydney," 2012, http://www.parracity.nsw.gov.au/_data/assets/ pdf_file/0016/115432/Greater_Western_Sydney_summary_statistics_November_2012_FINAL.pdf.

[42] Financial Stability Review, "Reserve Bank of Australia, Commonwealth of Australia," April 2017, https://www.rba.gov.au/ publications/fsr/2017/apr/.
[43] Australian Securities and Investments Commission (ASIC), "Australia's National Financial Literacy Strategy," 2017, http:// www.financialliteracy.gov.au/strategy-and-action-plan/financial-literacy-strategy.

[44] The Salvation Army, "Money Talks. Moneycare's financial literacy education program "You're the Boss"," 2017, https://salvos .org.au/need-help/financial-assistance/money-talks/.

[45] The Australian University, "Trauma and Grief Network. Reducing the mental health risks faced by children and adolescents by providing information and support for parents and caregivers," 2017, https://tgn.anu.edu.au/.

[46] Kids Matter, "An Australian mental health and well-being initiative set in primary schools and early childhood education and care services," 2017, https://www.kidsmatter.edu.au/. 


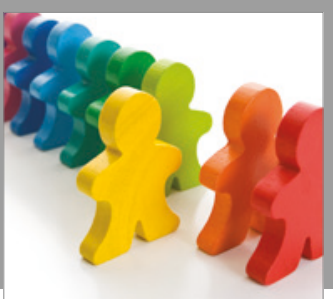

Autism

Research and Treatment
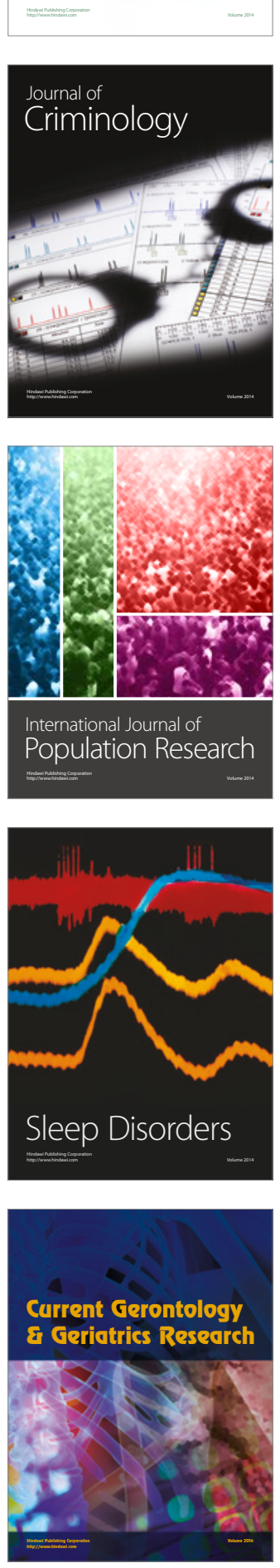

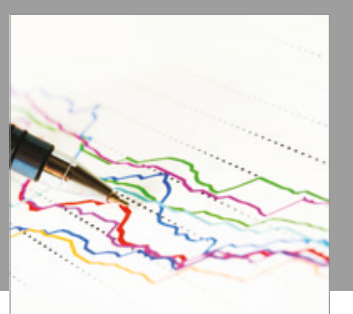

Economics

Research International

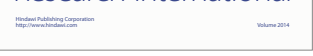

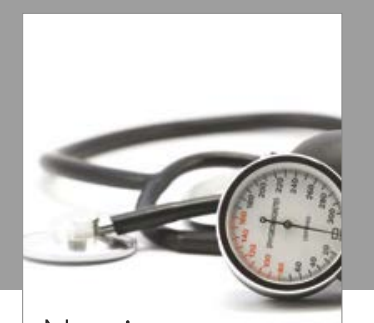

Nursing

Research and Practice

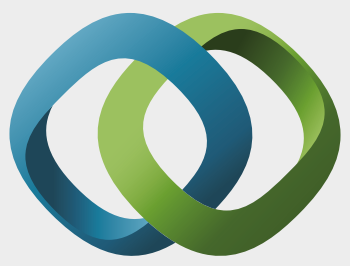

\section{Hindawi}

Submit your manuscripts at

https://www.hindawi.com
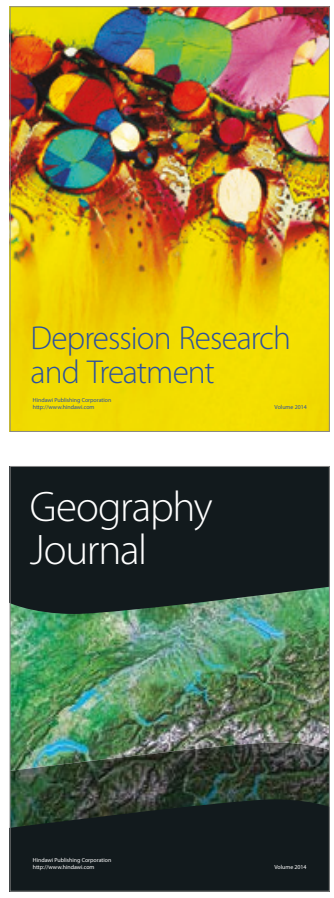
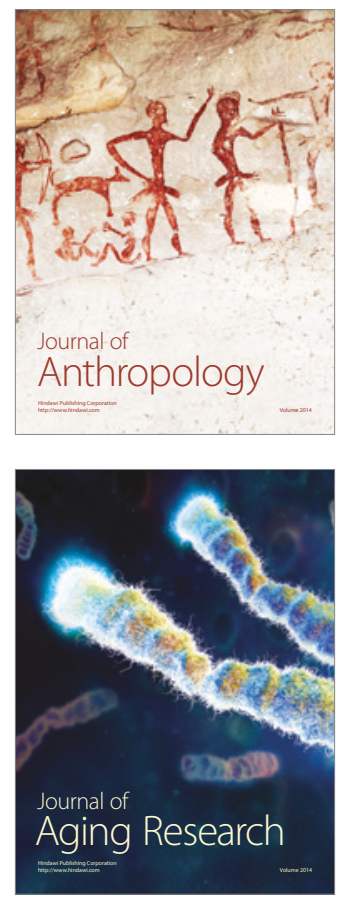
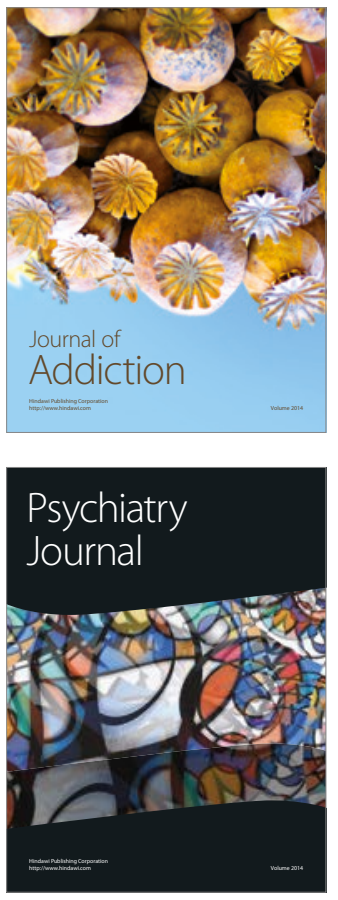

Child Development

Research

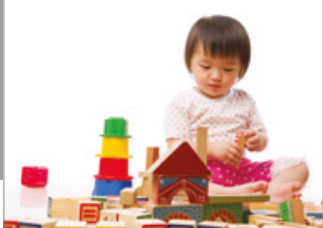

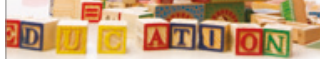
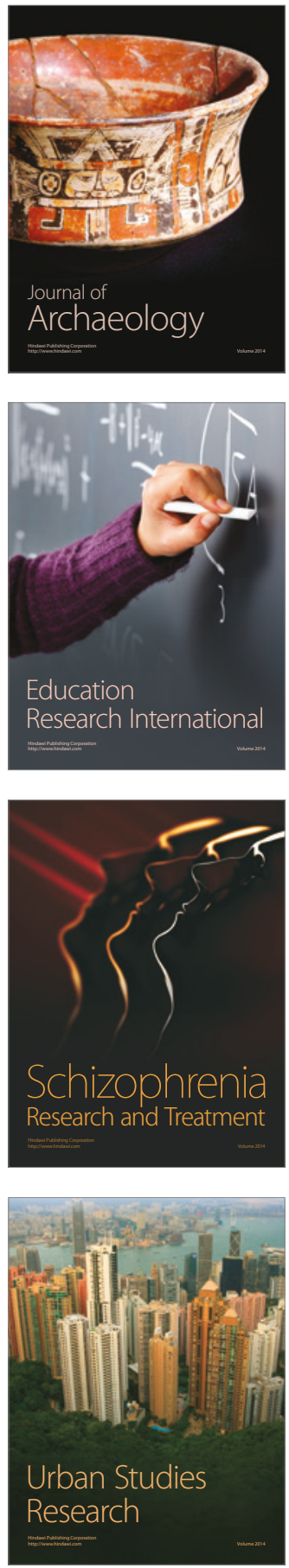